\title{
Battling in the Bronx: Social Choreography and Outlaw Culture Among Early Hip-Hop Streetdancers in New York City
}

\author{
Imani Kai Johnson
}

He learned from peers who didn't mince words or coddle hurt feelings, because battling was serious business. He tells me that in the mid-1970s, battling meant combat not competition. This one was led by two b-boying icons: Trac2 and Spy, teenage leaders of their respective crews. Though battles often took place in abandoned buildings, this one was on concrete. No cardboard. They were in Spy's neighborhood. Trac2 and his crew walked there, and as they moved between territories their community followed. Trac2's sister told him that a pregnant woman in a cab saw them walking and got out to join them. They arrived 75 people deep. The battle cypher, "an imaginary circle a b-boy creates in his mind to battle his opponent," nonetheless had material elements-mainly debris like broken glass that they swept away with their feet. The dance's repertoire was limited; rocking ${ }^{2}$ was more rudimentary then. Still, Spy was "the man with a thousand moves." ${ }^{3}$ He likely began with a basic toprock: one foot forward at a time, arms open just enough to bare his torso, presenting himself to the opposing crew, challenging them. Perhaps he'd add a short hop from one foot to the next, or James Brown-inspired shuffles, improvisations borrowed from pop culture as signature styles. A twisting dive to the ground transitions him to floor work: maybe front sweeps, or front-facing side-to-side crouched twists with kick-outs called cc's, or low to the ground spins in a tight circle some call a top spin. Each move had a name and was fired on opponents like a bullet, emblematic of the herky jerky and staccato style of "70s breaking. ${ }^{4}$ Trac2 had his crew take a knee and ordered them out one by one to battle. They returned to their knee when they finished their round, a gesture signifying discipline under his leadership. Trac2 still carries the scar on his left hand from a broken Coke bottle that cut him while he danced. He says he kept dancing, only getting it checked out when the battle finished. There were no handshakes afterward. They didn't even talk across crews until the next day. Losing meant forfeiting some money or maybe even their shoes. Trac2 doesn't name what he lost that day, but he and Spy would battle again, and eventually battle together.

Dr. Imani Kai Johnson (imani.johnson@ucr.edu) is an assistant professor of critical dance studies at UC Riverside. She specializes in African diasporic ritual cultures, dance ethnography, political theory, and black aesthetics with an emphasis on hip-hop dance. She is currently working on a manuscript about cyphers tentatively titled Dark Matter in Breaking Cyphers and is founder and chair of the Show \& Prove Hip Hop Studies Conference Series. 
pieced the above story together from Trac2, a 1970s era b-boy from the South Bronx. His varied battle experiences emphasize embodied and quotidian experiences within a complex cultural landscape of the South Bronx. ${ }^{5}$ Since video cameras were rare and expensive to these Bronx youth (Schloss 2009, 126), oral histories that detail 1970s hip-hop culture from a streetdance perspective are essential in the absence of visual documentation. Life in the South Bronx shaped how practitioners approached hip-hop, and in turn hip-hop provided a new cultural context for creative expressions of urban sensibilities. This correlation remains foundational to the ongoing life of hip-hop streetdance battles today. This article studies the relationship between South Bronx living in the 1970s and early 1980s among the first few generations of breakers and New York-based poppers and their battling practices. ${ }^{6}$ I draw on oral histories from b-boys Aby and Kwikstep, b-girl Baby Love, and popper Cartoon. While my research emphasis is on breaking, this era of battling demands looking beyond genre. Crews typically had members proficient in multiple streetdances, especially popping and locking, so that they were collectively a force in any battle. Hip-hop's "outlaw" persona is embedded in battling practices. My focus is on the relationship between their social choreography (the way a society compels people to move in and through the world) and four battling principles: survivalism, strategizing, nomadism, and illusionism. In turn, battles instill principles that are evident in the South Bronx's outlaw culture through a sensibility that counters dominant notions about their sociopolitical and racialized marginality.

My research is the product of a multisited study of cyphering practices at b-boying and hip-hop events in eleven North American cities and three European cities from 2005 to 2012. This work is primarily ethnographic, combining interviews of over seventy practitioners, field research at b-boying events, and research at public and private archives. I center the voices of practitioners throughout this piece, citing them at length when possible to showcase their nuanced perspectives, which I regard as informal theorizing about life and hip-hop. Thus, rather than perform academic distance, whenever possible I build on the practitioners' expertise in a manner that is readable to them as nonacademic experts in the field. My work, which examines the things you do not see or that are invisiblized (Gottschild 1996) in cyphers, asks us to "look" at battling through the lens of its organizing sensibilities. Social choreography enables a discussion of how everyday life in marginalized communities is essential to understanding streetdance.

\section{Social Choreography}

In this article, the term "social choreography" speaks to the ways the people of a given society are trained to move (both physically and spatially) and to contort and comport their bodies in keeping with and in (counter) production to a given social order. Bronx streetdancers were socialized to move in ways that were reinforced by their day-to-day experiences. Their social choreography is evident in the social dynamics of their dancing.

Andrew Hewitt's Social Choreography: Ideology as Performance in Dance and Everyday Movement (2005), which has been invoked by various scholars across disciplines, offers the most sustained discussion of this concept. Hewitt posits that in the relationship between art and society "dance has served as the aesthetic medium that most consistently sought to understand art as something immanently political; that is, as something that derives its political significance from its own status as praxis" $(2005,6)$. Understanding dance as praxis renders it inherently political precisely because embodied experiences of moving through the world as sociopolitical subjects of (in Hewitt's case, bourgeois) society shares an "aesthetic continuum" with dance, a medium wherein its practice and enactment are the realization of its lessons. Dance becomes the arena within which social orders are rehearsed and a "utopian social order" (Hewitt 2005, 21) or "fantasies" (30) of social order are performed for audiences. Social choreography thus "functions as a space in which social possibilities are both rehearsed and performed" (Pristaš 2007, 45). Though focused on questions of modernity, modern dance, and the ordering of bourgeois society, Hewitt's discussion lends itself to 
conceptualizing a relationship between how we are socialized to move through our worlds and how one physically moves in dance. He highlights how choreography both rehearses and performs social possibilities, capturing its performative capacity to ultimately constitute the very possibilities it performs. This gives us room to consider that battles are not just aestheticized combat, but performative acts of social possibility for embattled social actors in marginalized contexts.

Hewitt's investment in discussions of ideology and his own Eurocentric notions of modernity and bourgeois societal demands might account for why he eschews the impact of sociopolitical identities in his analysis. Thus, I also draw on Aimee Meredith Cox's monograph Shapeshifters: Black Girls and the Choreography of Citizenship, ${ }^{7}$ which shifts focus from modern dance to the social choreographies of young black women in a Detroit homeless shelter, centering on how race, class, and gender necessarily shape "the socially constructed meaning shackled to [their] bodies" $(2015,29$ my emphasis). Cox argues that in order to not rely on the "socially determined representations of their self-worth" (29), these young black women's choreography, or movement through the city and the shelter, "integrate... improvisation, borrowing, and sampling to disassemble and reconstruct current social realities" (30). ${ }^{8}$ Like Hewitt (2005), Cox draws on the capacity for social choreography to shape society and play with notions of reality; yet, Cox's point is that social choreography can act as a method for subversive moves that counter imposed devaluations of young black women's bodies.

Moreover, choreography here should be thought of as improvisational. In "Improvisation in African-American Vernacular Dancing"9 choreography is defined as, "the creative structuring ... of movement in the moment of ritual performance" (Jackson 2001, 44). ${ }^{10}$ The structural parameters of ritual battle cyphers are informed by the aesthetic and cultural imperatives of hip-hop cyphering practices, individual repertoires of dancers, and the "aural-kinesthetic environment"11 within which these dancers play (Johnson 2012). The choreographic element in social choreography is the creative structuring of movement within particular parameters, whether talking about a given ritual or everyday movement in urban environments.

Taken together, Hewitt (2005) and Cox (2015) demonstrate how social choreography is part of a production or counterproduction of a given social order. The social choreography of South Bronx youth in the mid-1970s to the early 1980s was counter to an expectation of their invisibility. As hip-hop scholar Joseph Schloss states, "As New York City was abandoned by the federal government and working-class neighborhoods were abandoned by New York City, youth in those neighborhoods were, in turn, abandoned by traditional institutions... . As a forgotten minority of a forgotten minority of a forgotten minority, their culture was almost totally ignored" $(2009,125)$. Their social choreography illuminates a culturally meaningful sensibility behind the spectacles created in battles.

\section{"True" B-Boyisms as Battling Principles}

Trac2 of Star Child la Rock Crew started breaking in 1973 and is now a repository of knowledge about Bronx streetdance cultures. During the course of an hour-long interview just following the Rock Steady Crew Anniversary Battle in 2006, he identified qualities of a "true b-boy" or breaker in battles. Trac2 articulates a breaking perspective, but the principles he recites have bearing on battling practices broadly, again because streetdance crews in New York were not comprised exclusively of breakers. While he did not list or number them, by the end of the interview I noted ten such qualities. To begin with, a "true" breaker (1) knows "the four elements of breaking" or the fundamental techniques of his or her practice. ${ }^{12}$ True breakers (2) battle, and (3) they do it for "ghetto celebrity status" (i.e., the respect of their community and their peers rather than solely for money or commercial fame). In addition, breakers are (4) illusionists, and they (5) "know the difference between a new move and a variation" of an already established move. True breakers 
are (6) "gypsies" who travel to battle other people. ${ }^{13}$ Moreover, they (7) know their opponents and their own repertoires. They are (8) strategic in battle, (9) improve as the battle continues, and (10) know that battles are won by "last man standing" and not by crowd response (Trac2 2006). Rather than deal with each element separately, I have grouped Trac2's list into four overarching battling principles to illuminate the underlying lessons built into them: survivalism $(2,9,10)$, strategizing $(1,7,8)$, nomadism $(2,3,6)$, and illusionism $(4,5)$. While my summation of Trac2's list of qualities into four principles is not formally recognized among breakers, these principles are a useful point of reference for embodied sensibilities learned from battling and for the underlying social choreographic principles enacted in battles.

Survivalism reminds us that in battles the goal is to be the last person standing, not just the crowd pleaser. In practice, Trac2 specifies that losers will begin to repeat their moves, give up, or be seduced into applauding for their opponent. Survivalism values perseverance after a trauma of some kind, which is to say that in order to survive one must contend with the possibility that one was not expected to survive in the first place. And while this might imply or outright signal victimization, hip-hop scholar Imani Perry clarifies: "Hip-hop resists victimhood, preferring ... the concept of the survivor. Survivors do not define themselves by their victimization, instead fighting against it and examining the social practices that lead to such violence" $(2004,111)$. Surviving is an ethic that refuses victimization, and it is embodied in the sheer act of dancing unremittingly yet always originally to maintain or achieve a strategic advantage.

The second quality, strategizing, reminds us that intervening in the social world through imaginative means also entails changing one's conditions into something advantageous to oneself. In a battle, strategizing necessitates understanding oneself and an opponent enough to launch a counterattack. As a battle principle, Trac2 adds that in order to strategize dancers need to know the extent of their skills while quickly assessing their opponent's capabilities. For example, do they have poor musicality, good balance, or sloppy footwork? Strategizing is embodied in performed threats (called burns) or mocking opponents to manipulate their reaction while preserving one's energy to go another round. Technical skills alone are not enough; improvisational play using all available resources is key.

Nomadism reminds us that streetdance is social and demands interaction with others beyond one's own circle to prove and elevate one's skills. This principle includes traveling to compete, which builds reputations for "ghetto celebrity status" and self-ranking. "Ghetto celebrity" is not bound to a particular ghetto, and in fact Trac2 names it in contrast to what he calls "a neighborhood dancer," someone only known around his or her particular neighborhood. Again, his focus is on constantly engaging beyond one's immediate surroundings. The crux of this logic is an implicit understanding that the ghetto is not a singular place. Despite the language of location, Trac2's use of the term "ghetto" alludes to a set of conditions experienced broadly, yet still in a contrast to mainstream society and versions of fame tied to wealth and recognition by white suburban audiences. Nomadism encompasses street-level social interactions in marginalized communities through competitive networking alongside a constant readiness to battle.

Finally, illusionism captures the magic of streetdance, making spectators wonder what they saw and how it was done. Yet, a "true" streetdancer should know the secret. Illusionism speaks to understanding the layers of cultural knowledge embedded in the dance and the implicit challenge to execute such moves just as flawlessly. Being able to dissect a move's nuances reflects both a degree of cultural knowledge and a sociocultural sensibility. Aesthetically, one need only look to b-boy Spy, a contemporary of Trac2's known as the "man with a thousand moves." Trac2 clarifies that the nickname does not mean that every move Spy did was brand new, but that his moves were variations on established moves thereby conveying a seemingly endless repertoire. This principle speaks to both an insider knowledge encoded in practices and the challenge to confound a sense of the real and the possible with new moves or unexpected variations. 
On their own, these principles give us some insight into the sensibilities that shape battling. Taken together though, they indicate distinct qualities of a sensibility about life and living in urban spaces such as the South Bronx. Survivalism recognizes hierarchical formations but does not capitulate to them. Strategizing anticipates obstacles that one must improvise through, thereby valuing training, preparation, and the creative use of all available resources. Nomadism speaks to perpetual preparedness to battle while expanding one's social competitive network for success in terms dictated by the community. Finally, illusionism masks expertise as the impossible actualized, performatively bringing a new reality into existence. The above are embodied principles about being in the world in a bold way that prioritizes hip-hop cultural values, which are outlaw cultural values.

\section{Outlaw Culture}

Strategies for navigating battle cyphers and the South Bronx intersect in relation to "outlaw culture." While hip-hop scholars have written about practitioners as outlaws, practitioners referred to themselves as "outlaws" from the outset, noting their antiauthority, counterconventional, sometimes criminal, combative, and confrontational styles (Chang 2005; Perry 2004; Rose 1994; Schloss 2009). For example, in an interview with Jeff Chang, graffiti writer Lady Pink states:

[Graffiti is] an outlaw art. When we train other graffiti writers, we're not training fine artists to exhibit in museums. We're training criminals. We're training kids how to take life in their own hands and go out there and hopelessly paint on some wall or some train that will do nothing for you except get you fame with other vandals and criminals. (Lady Pink quoted in Chang 2005, 121)

Playing on mainstream assumptions that graffiti is only ever vandalism, Lady Pink immediately launches into those values that it teaches and how it empowers youth in a way that is easily distinguishable from conventional professional aspirations.

Legal scholar Monica Evans (1982) and hip-hop scholar Imani Perry (2004), write about "outlaw culture" as a culture cultivated at the outskirts of mainstream values and social expectations because of racialized and classed subordination. In her analysis of black women's empowering outlaw practices, Evans writes:

Outlaw culture refers to the process by which African-Americans shift within and away from identities in response to mainstream legal systems and dominant culture. It describes a conscious and subconscious series of cultural practices constituting life at the margins. Marginality is thus a strategy for carving out spaces in which to maneuver and resist. $(1982,268)$

It is not just that "outlaws" are such because they are seen by the mainstream as dangerous and deviant, but that the marginal positionalities from which they "carve out" meaningful existences are in purposeful opposition to the mainstream. Outlaw culture contextualizes a social choreography that carves out greater mobility, flexibility, and visibility despite marginalized positionalities, thereby countering socially constructed meanings shackled to urban and working-class black people's bodies and homes.

Perry elaborates on this concept specifically in relationship to hip-hop culture, specifying that outlaw culture "articulate[es] a kind of power within the hood, an overwhelmingly powerless context, and an exploitation of the power created by fear of the hood experienced by outsiders" $(2004,104)$. The colloquial reference to the 'hood, ${ }^{14}$ a concept that sheds some of the stigma of terms like "ghetto" while preserving the communal quality of working-class urban life, speaks to an insider sentiment, one that recognizes forms of life within a context that is interpreted by outsiders through 
a lens of fear. Perry draws explicit attention to both the power in this positionality and a knowing manipulation of mainstream expectations of what it means to be from the "hood. In fact she names one of her chapters "glorious outlaw," in recognition of that power and its rich possibilities. By extension, outlaw culture produces a repertoire for living within particular environments that are attuned to its values and codes.

Outlaw sensibilities learned in the Bronx are part of the experience of hip-hop culture. Hip-hop was explicitly experienced as a counter to the crucible of state neglect and marginalization of the South Bronx. In his 2018 documentary titled Everything Remains Raw, locker and documentarian Moncell "Ill Kosby" Durden features a 2007 interview with popper Mr. Wiggles; the film shows the two men sitting in a Boston diner and looking at a series of photographs of the Bronx in the 1970s. ${ }^{15} \mathrm{Mr}$. Wiggles identified the photos taken near the block where he grew up and then launched into a description of life behind the black-and-white photos of abandoned and burned-out buildings:

\begin{abstract}
You could find anything in these buildings-bodies. You smell the bodies being dumped into the building. Everything was sold out of those lots and buildings, and abandoned buildings. It wasn't crack back then. It was dustheads and heroin addicts... . Me and all my friends... . That young I was already in the street in the Bronx, running around..., witnessing crazy shit; witnessing rumbles happening in Echo Park. Watching people walk in and crawl out. It was crazy. It was hectic. It was really scary man. Hip-hop was scary during that time. And we didn't call nothing hip-hop. We didn't look at anything as culture. It was just something to do to keep our minds off of the bullshit that we had to deal with on a regular basis. And those parts of the Bronx, to me, in my opinion are the reason why hip-hop was so important - it was that one gift that God was able to give us to help us get past all that b.s. (Durden 2018)
\end{abstract}

In his comments, Mr. Wiggles repeatedly referenced two modes of activity: their running around and their witnessing "crazy shit" not typically associated with childhood. One implication is that they constantly traversed their "hood and as a result had unprecedented access and exposure to violence. To be clear, though, such violence is not exclusive to poorer neighborhoods. Drug addiction and overdoses, murder, and peer-to-peer assaults happen in the suburbs too, but wealth, white privilege, and political clout allow for such acts of violence to be rendered private rather than aspects of public life. The public nature of this violence accounts for Mr. Wiggles's second point of emphasis: "witnessing" (witnessing rumbles, addicts, and bodies). To be a witness is not just to see something, but to know it and attest to that reality to others. These directives signal aspects of a community's social choreography, which entailed a sense of Mr. Wiggles's 'hood's boundaries even in the face of his and his peers' capacity to move through it with seeming unbounded access. In other words, Mr. Wiggles and his and his peers were not limited by property rights but by invisible codes imposed by street culture and social relations in the shadow of the state, which failed to productively intervene. They learned to stay mobile, to witness but not linger, to travel in groups, and to take solace in hip-hop. Ultimately, their social choreography comes to inform their actual choreography in battles.

To be clear, the outlaw nature of hip-hop is not simply a euphemism for illegality or violence; rather, it captures entire dimensions of social life that includes but is not exclusively comprised of a loose relationship to the law. From the absurd level of precarity built into people's everyday lives, Mr. Wiggles' story suggests a social choreography developed out of necessity. These lessons played out in how people's bodies moved through their 'hood, demonstrating a compositional capacity from marginal positionalities. This contextualizes hip-hop's coming into being.

s.




\section{Bronx Tales}

Cypher rituals bring an outlaw sensibility into expression. The following tales relay lessons learned by young men (the predominant practitioners during the early days of hip-hop) in coming of age in the South Bronx and by extension why those lessons have bearing on their dancing. Though these narratives illuminate specific principles, qualities of all four principles are evident in each story. I quote at length to allow for the full expression of the dancers' expertise.

\section{Surviving and Strategizing at the Clubhouse}

That youth took advantage of marginal spaces like burned- out and abandoned buildings scattered across the South Bronx is emblematic of hip-hop's outlaw culture. ${ }^{16} \mathrm{Mr}$. Wiggles describes them in the following way: "The landlords were burning down the buildings to collect on the insurance. The mafia was buying the buildings on purpose, burning them down with people in them, giving them very little notice. And then they [the city] would put them [homeless families] in a relo' building" (Durden 2018). The state's response of building relocation (i.e., relo') homes, "where when your building got burnt out, they already had a building to put you in," reflects its attempt to patch the situation by building temporary housing for homeless families rather than by addressing the underlying structural causes. ${ }^{17} \mathrm{He}$ concludes this description with the unsettling question, "Now don't that look systematic to you?" On its surface, Wiggles's discussion seems to fall in line with persistent narration of the South Bronx in the 1970s: as a place in crisis and characterized by violence and lack. Yet, his words are more than sociological evidence of a ghetto trope. They exemplify why hip-hop was a gift that kept him and his crew protected.

Crews are peer-based social organizations, modeled after gangs but constitutive of and able to mobilize an immediate dance community. For Aby's crew, The Bronx Boys/Bronx Girls Rocking Crew, these same burned- out buildings were their "clubhouse." By placing their bodies in otherwise dangerous spaces, his crew of fifty or more adolescents and teenagers staked claim to forfeited property, taking it over, and reconfiguring a symbol of the borough's deterioration into a resource. Their strategizing valued using those spaces rather than avoiding them out of fear or abandoning them for profit:

We saw an abandoned building around our area. Nobody living, burned down. We'd go in there: everybody gets a floor. We used to go take uh-we used to steal the extension cords from our houses or we used to go into Woolworths, (at that time there was a store called Woolworths) and steal power cords. And we'll connect them to the light outside, bring it all into the building. All the way, every floor, and everybody'll have lights, electrical lights. We'll get crates, milk crates, and wood, and mattresses-old mattresses burnt out or trashed out—we'd go and put it and we'll furnish our apartments. So everybody had a floor. An abandoned building mind you; this is a building that's been abandoned. So it's like, it's our building. That'd be our second home. Whoever wanted to run away, you run away you run in there. You stay there. We had shelter. In the winter we cold, but we had shelter. When it's raining, we go in the house, we go in our apartment. That was ours. Nobody could take it away from us but the state, police, and they really never did 'cause they was afraid to even go up in there. The only ones that we would bump into there, they were the drug addicts. That's it, you know. We'd go up our flights see one by me with a vein, you know, shooting up. And, [we'd say] "Yo! What's up?!" and keep on going, keep it moving. We never was scared 'cause we had a group! We had a big group. (Aby 2007)

Aby's initial emphasis is on a certain kind of independence to cultivate his own family and his own home without parental rules. He and his crew took advantage of what was available to them: stolen and found objects, other people's trash, discarded property. The overwhelming tone of his story is 
not of victimhood, but of subsistence-everybody had a floor, lights, makeshift furniture, beds, shelter in poor weather, and a place to go when they ran away from home. Aby and his crew members met their needs in the least expensive ways. Note his implied right to claim abandoned property, to seize it from its uselessness and recreate it into a resource. His repetition of "an abandoned building" makes the case that he and his friends were not trespassing. That they stole from their homes, from Woolworths, and the power company was beside the point. The fact of the building being abandoned in the first place was the problem. Moreover, moving through the clubhouse as a crew meant always having protection, backup, and resources that supplemented everyday needs. From their positionalities on the symbolic outskirts of society, Aby and his crew actively superseded the state's authority and created their own standards for living that supported their survival. Their strategizing allowed them to work against conditions meant to perpetuate economic lack and social immobility.

\section{Illusionism Through Discipline and Training}

Cartoon is a little-known but dedicated popper who grew up in the Bronx and never got to travel to the West Coast (where the dance originated), but instead traversed his borough to learn as much as possible about the dance. Though Cartoon was without a crew, popping shaped the early direction of his life. In a 2006 interview, Cartoon began his story, not at birth, but with his first time seeing live popping. He spoke with such passion that he regularly stuttered, almost forcing out every last, pertinent detail. The beginning of his journey is rich in the cadence of his enthusiasm about the people and places that prompted his love of popping:

So I seen Pauly G and Loose Boots and I was like, wow! I seen these two people floatin' all over the floor on $42^{\text {nd }}[$ St.]. ... And I was like wow! People can float all over the floor and defy gravity with their body! Now that! I find that to be very intriguing. So, I had a couple of friends with me-it was Thanksgiving in 1979-and they laughed and said, "You never gonna learn how to do that." So I took it home with me and I practice it. And I practice and I practice and I practice, you know? And then finally, I got the backslide. And I got the front slide. So then ... I went to Kips Bay Boys Club and then, I met, um... Wiggles. I met Wiggles. And Wiggles - he was the first person I ever seen who was doing waves like water through his body.... So at the time I was going to Gompers [High School], and I met a guy named Al. And $\mathrm{Al}$ was down with the Electric Company. I was learning from Al. And $\mathrm{Al}$ was like, showing me how to do the arm wave, and how to do the tick, and how to do the backslide, and do the sideslide.... I would dance, and I would practice ... and then, at that particular time there were a lot of contests going on. There was the-the-the "Lets Boogie" contest over at Skatin' Palace. And I went to that contest, and I competed in that contest.... I didn't win that contest. But, I [got] a lot of experience.... [Eventually] I would battle people, and I never lost. (Cartoon 2006)

This is how Cartoon began a 45-minute narration of his life, unprompted and with few interruptions. I initially struggled to understand his story, but in time I began to appreciate its details. Though he starts out on 42nd Street in Manhattan, he makes his way to the Kips Bay Boys Club, which had once been located in Midtown Manhattan but moved to the Southeast Bronx in 1969 (Kips Bay Boys \& Girls Club 2018). ${ }^{18}$ From the Boys and Girls Club, Gompers High School near East 145th Street factors into the story, but only as a site for dance and little else. Eventually though, Cartoon would drop out to pursue his art. The story ends at the now defunct Skating Palace, once on the corner of Rosedale and Soundview Avenues, where he first battled. Cartoon's nomadism re-mapped the South Bronx into sites and networks for dance training, and popping allowed him literally to occupy spaces differently than he had before: floating, gliding, waving, and sliding all over the place. 
Cartoon learned about the possibilities of his own body because of a certain approach to discipline. For example, he states, "Al was my teacher, but I would go to Wiggles' house after school, and I wanted to learn the dance so bad. I cut school just to learn the dance. And Wiggles was the type of person, he says, 'I'm only gonna show you once. ... One time, and you don't get it, too bad.' And that's what he would do. He was the one that really inspired me." Cartoon had a series of weak but developing social ties that popping made possible. Proving himself became a constant effort as that recognition depended on his capacity to learn quickly, listen, and dance to his peers' liking. Those new relationships were not simply "available" to him; Cartoon had to earn his peers' respect by demonstrating his respect and even reverence for the dance. He eventually learned popping's illusions. ${ }^{19}$ His embodied experience of discipline in training plays out in part as requisite commitment to the dance, which opened the doors to popping's secrets.

Cartoon's training can be contrasted with Baby Love, who (though a b-girl with a crew) had experiences that provide some context for the experiences of young women in these spaces. Baby Love was the first popularly recognized b-girl, formerly of the Young City Girls and the Rock Steady Crew, and is currently with the all-women multielement group called Collective7. Women experienced gendered challenges to their learning breaking, from parental restrictions to contending with expectations of appropriate femininity (Rose 1994, 48; Johnson 2014, 17-18). Baby Love was among only a handful of b-girls in the early 1980s, and her experiences with training were quite different from Cartoon's. In a 2007 interview with me she discussed aspects of this difference:

\section{IKJ: Give me some background as to why you think there was not as much support around you developing in areas other than footwork.}

BL: I'd like to say probably because of my size, you know, not being strong enough to hold my body. Maybe that's not true. And I think I will never know. You know I think we'll never know that it was because, "Oh, let her just do the footwork and that's good enough. We don't have to teach her anything else.” I don't know if their perception was that I didn't want to learn more. You know, I guess I will never know. Those are questions that I don't have answers to. You know, I can speculate. I will always speculate. But I won't let it take away what I have today with the women that I'm involved with, with Collective 7, and what that represents to me. And what women in hip-hop represents to me. Because I am a woman in hip-hop. (Baby Love 2007)

Baby Love's experience was decidedly less regimented for reasons that she never fully understood. Our shared assumption is that sexism played a part. Tricia Rose notes that among the barriers to participation for b-girls were sexist attitudes among b-boys that "heavily discouraged [most girls] from performing break moves because they were perceived by some male peers as 'unsafe' and 'unfeminine"' (Rose 1994, 48). The implication is that the support Baby Love did receive from her crew, as discussed later in the interview, both in teaching her certain moves and helping her avoid punishment for hanging out with them in the first place, this kind of support never mitigated the risk of her being tokenized, which was a strong possibility for women in crews at the time, whether they were poppers or b-girls. Discipline and precision were demanded of Cartoon in a way these characteristics were only selectively expected of Baby Love, who would go on to much greater name recognition. By the late ' 80 s, Baby Love traveled abroad as a b-girl, then parlayed that confidence into college, making moves toward Broadway in her youth. Today, her name is still recognized and respected.

Unlike Baby Love, Cartoon never achieved the fame he once desired. At our first introduction, for example, he repeatedly referred to his being cast in the 1984 hip-hop movie Beat Street, but his part ended up on the cutting room floor. He kept the proof on him: a paystub for $\$ 542$, rather than the $\$ 25$ paid to extras. The experience taught him a lot about the entertainment industry and the 
fleeting nature of mainstream fame. While he achieved neither mainstream fame nor "ghetto celebrity," he was recognized in local circles as a neighborhood dancer. ${ }^{20}$ Cartoon's tone was tinged with a nostalgia for what could have been-not unlike the story he tells me of his father who was once booed at the Apollo. Yet, in the context of hip-hop, practitioners can redeem their reputations with the next win. Hence, Cartoon's early loss and purported subsequent victories are a testament to his hard-won skills.

Cartoon's own narration places him within a lineage of poppers and thus within a history of hip-hop. His story outlines a sensibility wherein anyone can have a place in the (local) annals of hip-hop history precisely because that history is open to those who earn a place in it. He finished our interview by stating that, "It was the most beautifullest time of my life." Then he looked at the camera and gave "a very special thanks," "props," and "love," to Mr. Wiggles, Popmaster Fabel, DJ African Bambaataa, Poppin' Pete, Boogaloo Sam, the late Skeeter Rabbit, and DJ Shakes for "passing on the information" and giving him what he "necessarily needed." In thanking someone like Skeeter Rabbit who died not long before our interview, poppers like Sam and Pete whom he had never met, and DJs Shakes and Bambaataa (a man anchored to the history of hip-hop), Cartoon's list is more than an expression of gratitude. He paid homage to his cultural elders, a signal of his continued commitment to and deference for the culture.

\section{Nomadism as Two Sides of the Street}

Nomadism was a functional necessity for breakers. Not everyone used to break; breakers had to travel to find each other. Once found, battling helped breakers build their social networks. Kwikstep, of Full Circle Productions, spoke to me about his nomadic journeys as a b-boy to different schools and boroughs during his adolescence.

I was in the streets and I knew that there were two sides to the streets. ... Um, there's a saying in Spanish: mira pa frente, no mire palado; tu es un santo, pero tu no eres babalao. Meaning look forward, don't look to the side; you might be a saint but you're not God. That means mind your fucking business, and don't think you too bad for anything because you will get tested. I knew that at a young age. Where I was going, I kept focused [on] where I was going. I didn't look at anybody. I went to go break. That's it. And after awhile they'd be like, "Yo, I seen Shorty on this block all of the time. What's he doing man?" I mean, they saw me at the jams and block parties, in the school yard. Like, "Yo, money's nice." 'Cause thugs, they love dancers. [Dancers] got skills that [thugs] don't got. Plus, girls come around you. So you know, they have a different reason why they hang around you. But it's, part of it is admiration. So, there's a little bit of respect there. (Kwikstep 2008)

As a principle, nomadism speaks to the necessity of travel; as an embodied experience, Kwikstep emphasizes how he travelled. Kwiksteps' primary lesson was simple: mind his business and stay on his path. He understood this in a proverbial kind of way-a folk wisdom he rattled off so quickly that my beginning Spanish skills could barely keep up. The message was nonetheless powerful: "you might be a saint, but you're not God." In Yoruba-based spiritual practices in the Americas and in West Africa, the babalao is a spiritual leader who offers healing or divination services as a kind of high priest, a different kind of MC (a master of spiritual ceremonies). ${ }^{21}$ Therefore, if the rules of the streets are that you can be saintly but never above the fray of street life, then on the one hand, Kwikstep highlights needing to have walked with an unwavering focus, watching out for what he could not predict or control. On the other hand, his focus on dance helped to paint a seductive mystique. He became a new kind of community figure: a b-boy. Within the larger social landscape, b-boys cultivated an aura unique to them, one that borrowed from "both sides of the street" and balanced looking outward with caution while compelling others to look at the illusions they 
projected. Kwikstep built community through nomadism, but he reminds us that moving boldly yet cautiously is necessary to negotiate the unpredictability of any given environment.

As the above examples make evident, the social environment taught a repertoire for living in the South Bronx in the 1970s and ' 80 s, intersecting an outlaw social choreography with a burgeoning outlaw aesthetic. These intersections were themselves productive: of the reappropriation of private property, of compulsory respect built into training, or of new cultural identities. Though these stories are not exhaustive, they all reveal distinct insights about South Bronx living in a hip-hop context.

\section{Conclusion}

These first generations of breakers and New York-based poppers who grew up in the South Bronx contributed to the creation of a culture that basked in its own invention, celebrated its own practitioners, and valued the sensibilities that perpetuated their worlds. Rather than private ownership, consumerism, and mainstream fame, they spoke of squatter's rights, do-it-yourself artistry, and ghetto celebrity statuses. Their social choreography taught outlaw "values, norms, and ideals in contrast to those embraced in American society," which, Perry argues, "discount the complexity of choices faced by those black and poor in the United States" (2004, 103-104). The outlaw in her description is anti-status quo and opposes the racial and classed marginalization.

Battles are not solely or simply contests over bitter rivalries. Their foundational sensibilities reinforce the manner in which things are done, rather than what is done. Battles carry principles of a Bronx cultural outlawry, activate a set of culturally meaningful repertoires, critique mainstream values, and teach these lessons to new generations of practitioners. The social choreography in the 1970s and early 1980s that informs battling principles, a choreography that carries outlaw values, continues to matter as hip-hop evolves. I see it in connection to Halifu Osumare's notion of "collective marginalities," a concept that addresses the ways that hip-hop's aesthetics invite global connections between marginalized communities in particular (Osumare 2001). Osumare's concept evidences the ongoing capacity of outlaw cultural aesthetics in hip-hop to appeal to marginalized subjects. Hip-hop streetdance battles are aesthetic expressions of a marginalized sensibility made beautiful.

\section{Notes}

Thank you Angela Marino, Zoila Mendoza, and the UC Berkeley graduate students involved in the "Embodied Knowledges in Ritual Processions, Cyphers \& Festivals" for helping me reshape this chapter. Special appreciation to Melissa Templeton, Anthea Kraut, Jens Giersdorf, and Yvonne Daniel for their critical feedback.

1. Trac2, 2006, personal communication with author, July 28; Trac2 and Kwikstep, 2007, video recorded interview with author and Moncell Durden, Boston, May 26.

2. 1970s b-boy Trac2 cites battling as a derivative of rumbling (fighting, gang fights).

3. Trac2, 2006, personal communication with author, Manhattan, July 28.

4. See Freshest Kids (2002) directed by Israel.

5. The South Bronx, credited as the birthplace of hip-hop culture's multiple elements (DJing, MCing, breaking, graffiti writing), acts as a proxy for New York City as a whole as the terrain for these early generation streetdancers.

6. Popping is an umbrella term for several different funkstyles (e.g., roboting, tutting, boogaloo, ticking), but it also falls under the umbrella of hip-hop. Popping was born in California, developed out of Bay Area and Central and Southern California social dances, and innovated by figures

like Boogaloo Sam. Showcased on nationally syndicated shows like Soul Train that featured 
California social dances, these genres were adopted by New York youth and incorporated into a burgeoning cultural movement now called hip-hop. I use "hip-hop streetdances" as a catchall for breaking/b-boying, which is typically associated with hip-hop, and for funkstyles that are now associated with hip-hop culture. See Naomi Elizabeth Bragin (2015, 46-47).

7. While there are different works about social choreography in analyses of dance (mainly the waltz), Cox's discussion more aptly suits the context of my research.

8. Cox's use of performance terms, especially terms like sampling that specifically invoke hip-hop culture, highlights the convergence of social strategies and hip-hop aesthetics.

9. Now publishing under the name Cleis Abeni, this article was originally published under the name Jonathan Jackson.

10. One can liken this to a score in modern dance performances that sets the parameters for action while allowing artists to improvise their way through the criteria, which are set not by a choreographer, but by a set of conventions endemic to the tradition itself. The author elaborates that improvisation in black vernacular dance has two overlapping and interrelated fields of symbolic physical interaction: individuation, or the negotiation of individual style within and according to the aesthetics that inform the dancing, and ritualization, or the levels of movement organization among performers as they make community (Jackson 2001, 46).

11. The aural-kinesthetic speaks to the simultaneity of music and movement in social dance cultures.

12. To Trac2, breaking's four elements are top rocking, drops, floor work, freezes. Other dancers conceptualize the genre's parts differently, specifying footwork, air moves, or spins, all of which are part of Trac2's definition of "floor work." This particular point is still applicable to other genres, like popping, in broader terms of appropriate technique.

13. "Gypsy" is a pejorative for the Romani people and is associated with criminality and poverty.

14. Short for neighborhood.

15. In 2008, Moncell Durden provided permission and access to his full interview with Mr. Wiggles, conducted for his documentary Everything Remains Raw in advance of the film's completion. In January 2018, Durden decided to release the documentary independently via YouTube. com. In consideration of the Dance Research Journal's readership, I have used the YouTube.com film, which readers can access directly. See Everything Remains Raw, http://www.youtube.com/ watch? $\mathrm{v}=16 \mathrm{~s} 5 \mathrm{KThmv} 7 \mathrm{U}$.

16. In Can't Stop Won't Stop, Jeff Chang writes that in the South Bronx alone between 1973 to 1977 there were 30,000 documented incidents of arson, thus contributing to the national image of the South Bronx as a "war-zone" $(2005,15)$. Howard Cosell's on air proclamation that, "The Bronx is burning," during the 1977 World Series at Yankee Stadium (where he could see the smoke and flames of the five-alarm fire burning the abandoned Public School 3 east of the stadium) painted that picture for a national audience $(2005,10)$. Despite the nationwide economic crisis and the citywide problems, what the nation understood was captured in the title of a 1977 article in the New York Times, "Bronx: A Symbol of America's Woes." The sentiment was also echoed in other articles. See Richard Severo, "Bronx a Symbol of America's Woes," New York Times (1977, October 6); Lee Dembart, "Carter Takes 'Sobering' Trip to South Bronx," New York Times (1977, October 6); Joseph P. Fried, “The South Bronx, U.S.A.," New York Times (1977, October 7); Staff Writer, “The Trip to the Bronx," New York Times (1977, October 6). The story of hip-hop's beginnings in the South Bronx has been treated by various works, including Steven Hager's Hip Hop: The Illustrated History of Break Dancing, Rap Music, and Graffiti (1984), David Toop's Rap Attack (2000), Tricia Rose's Black Noise (1994), and Fricke and Ahearn's Yes, Yes, Y'all (2002), or Jeff Chang's Can't Stop Won't Stop (2005).

17. Implicating the mob and landlords may seem conspiratorial to some, but Evelyn Gonzalez's The Bronx details the political and economic incentives for the temporary and unofficial abandonment of the South Bronx by the state, private owners, and some residents. Her study details the housing policies that encouraged redlining in the 1930s, the subsequent "white flight" in the 1940s and 1950s, and the social disorder in the United States in the 1960s that set the stage for 
Mr. Wiggles's South Bronx life. The South Bronx became a destination for those with few other choices-poor blacks and Spanish-speaking (im)migrants (2004, 111). Community organizations like Advocates for Children (AFC), a nonprofit educational advocacy organization, put particular focus on those families and children living in the "welfare hotels" for poor, newly-homeless families, what Wiggles knew as "relos." More than a decade after the 1977 New York blackouts and President Carter's subsequent visit to the South Bronx, homeless hotels were still being emptied. AFC issued a "Testimony on Progress Made by New York City in Emptying the 'Welfare Hotels' and Relocating Homeless Families" at a congressional hearing on May 8, 1989. The organization noted both its progress in housing eight hundred families the previous year and the offset of such progress-the inefficiency of quick moves that "caused more disruption and hardship, often leaving families stranded." (Advocacy for Children 1989)

18. See Kips Bay Boys \& Girls Club, "Who We Are: History, Mission, \& Vision.” http://www. kipsbay.org/history-mission-and-vision.

19. For example, as Naomi Bragin explains, though a move may appear as a shoulder shrug, it's actually a muscular contraction that a shrug emphasizes but does not create $(2015,47)$.

20. I was introduced to Cartoon at a Bronx block party by a popper named Peaches, who insisted that he was someone I should speak with-a sign of his local recognition.

21. Sometimes spelled "babalawo," this figure is recognized in Yoruba-based spiritual systems in Latin America, including Cuban Lucumí and Brazilian Candomblé. There are many sources that delve into the intricacies of this figure. One such source is The Handbook on Yoruba Religious Concepts by Baba Ifa Karade (1994).

\section{Works Cited}

Aby. 2007. Video recorded interview with author, Ft. Lauderdale, March 18.

Advocacy for Children. 1989. "Testimony on Progress Made by New York City in Emptying the 'Welfare Hotels' and Relocating Homeless Families." Press Release, May 8.

Baby Love. 2007. Video recorded interview with author, Minneapolis, June 29.

Bragin, Naomi Elizabeth. 2015. "Black Power of Hip Hop Dance: On Kinesthetic Politics.” Ph.D. diss. University of California: Berkeley.

Cartoon. 2006. Video recorded interview with author, Bronx, September 28.

Chang, Jeff. 2005. Can't Stop Won't Stop: A History of the Hip-Hop Generation. New York: St. Martin's Press.

Cox, Aimee M. 2015. Shapeshifters: Black Girls and the Choreography of Citizenship. Durham: Duke University Press.

Dembart, Lee. 1977. "Carter Takes 'Sobering' Trip to South Bronx.” New York Times, Oct. 6.

Durden, Moncell. 2018. Everything Remains Raw. Youtube.com. Accessed May 6, 2018. https:// www.youtube.com/watch?v=16s5KThmv7U.

Evans, Monica. 1982. "Stealing Away: Black Women, Outlaw Culture, and the Rhetoric of Rights." In Critical Race Theory: The Cutting Edge, edited by Richard Delgado, 263-98. Temple University Press.

Fricke, Jim, and Charlie Ahearn. 2002. Yes Yes Y'all: Oral History of Hip-Hop's First Decade. Oxford: Perseus Press.

Fried, Joseph P. 1977. “The South Bronx, U.S.A.” New York Times, Oct. 7.

Gonzalez, Evelyn. 2004. The Bronx. New York: Columbia University Press.

Gottschild, Brenda Dixon. 1996. Digging the Africanist Presence in American Performance: Dance and Other Contexts. Westport, CT: Praeger.

Hager, Steven. 1984. Hip Hop: The Illustrated History of Break Dancing, Rap Music, and Graffiti. New York: St. Martin's Press.

Hewitt, Andrew. 2005. Social Choreography: Ideology as Performance in Dance and Everyday Movement. Durham: Duke University Press. 
Israel director. 2002. Freshest Kids: A History of the B-boy. Crazy Legs, Trac2, Kool Herc, and Popmaster Fable (performers). DVD. QD3 Entertainment.

Jackson, Jonathan David. 2001. "Improvisation in African-American Vernacular Dancing," Dance Research Journal 33 (2): 40-53.

Johnson, Imani Kai. 2012. "Music Meant to Make You Move: Considering the Aural-Kinesthetic," Sounding Out! Sound Studies Blog. Accessed June 18, 2017. http://soundstudiesblog.com/2012/ 06/18/music-meant-to-make-you-move-considering-the-aural-kinesthetic/.

. 2014. "From Blues Women to B-Girls: Performing Badass Femininity." Women and Performance 24 (1): 15-28.

Karade, Baba Ifa. 1994. The Handbook on Yoruba Religious Concepts. Weiser Books.

Kips Bay Boys \& Girls Club. 2018. "Who We Are: History, Mission, \& Vision." Kipsbay.org. Accessed March 25. http://www.kipsbay.org/history-mission-and-vision.

Kwikstep. 2008. Video recorded Interview by author, Manhattan. August 8.

Osumare, Halifu. 2001. "Beat Streets in the Global Hood: Connective Marginalities in the Hip Hop Globe." Journal of American and Comparative Cultures 24, (1-2): 171-81.

Perry, Imani. 2004. Prophets of the Hood: Politics and Poetics in Hip Hop. Durham: Duke University Press.

Pristaš, Goran Sergej. 2007. "Andrew Hewitt: Choreography is a Way of Thinking about the Relationship of Aesthetics to Politics.” Frakcija 42: 44-50.

Rose, Tricia. 1994. Black Noise: Rap Music and Black Culture in Contemporary America. Hanover: Wesleyan University Press.

Schloss, Joseph G. 2009. Foundation: B-Boys, B-Girls, and Hip-Hop Culture in New York. Oxford: Oxford University Press.

Severo, Richard. 1977. "Bronx a Symbol of America's Woes.” New York Times, Oct. 6.

Staff Writer. 1977. "The Trip to the Bronx." New York Times, Oct. 6.

Toop, David. 2000. Rap Attack \#3: African Rap to Global Hip Hop. Expanded 3rd ed. London: Serpent's Tail.

Trac2. 2006. Personal communication with author, Manhattan. July 28.

Trac2 and Kwikstep. 2007. Video recorded interview by author and Moncell Durden, Boston. May 26. 


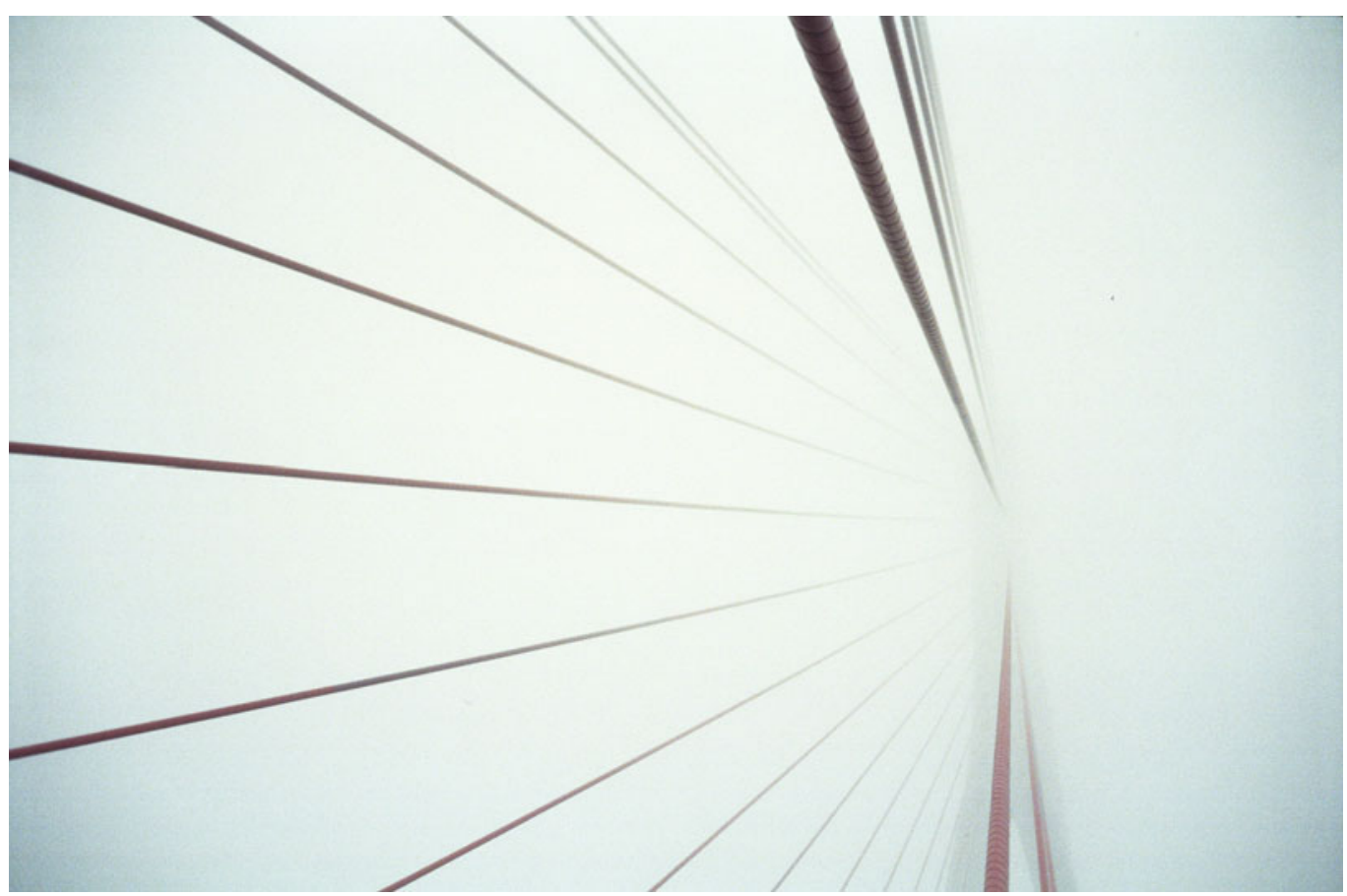

